\title{
Configuration of Palliative Care Clinics and Integration with Home Health Care Services: Current Practice in Turkey
}

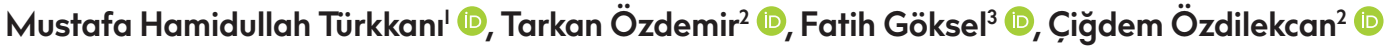 \\ 'Department of Pulmonology, Sincan Dr. Nafiz Körez State Hospital, Ankara, Turkey \\ 2Department of Pulmonology, University of Health Sciences Dr. Abdurrahman Yurtaslan Oncology Research and Training Hospital, \\ Ankara, Turkey \\ ${ }^{3}$ Department of Radiation Oncology, University of Health Sciences Dr. Abdurrahman Yurtaslan Oncology Research and Training Hospital, \\ Ankara, Turkey
}

ORCID iDs of the authors: M.H.T. 0000-0003-I503-7343; T.Ö. 0000-0002-9344-7586; F.G. 0000-0003-3164-0767; C.0̈. 0000-000I-5335-057I.

Cite this article as: Türkkanı MH, Özdemir T, Göksel F, Özdilekcan C̣. Configuration of Palliative Care Clinics and Integration with Home Health Care Services: Current Practice in Turkey. Cyprus J Med Sci 2020; 5(3): 196-9.

\section{BACKGROUND/AIMS}

The establishment of palliative care clinics (PCCs) and the integration between PCCs and home health care are important for both patient comfort and disease-related cost reduction. We aimed to analyze PCC distribution and structure of state hospitals along with human resources, and to evaluate the integration of PCCs with home health care services in Turkey.

\section{MATERIAL and METHODS}

Data of PCCs started between January 2015 and February 2017 were analyzed in this study with the help of data obtained from the Turkish Ministry of Health.

\section{RESULTS}

PCCs are available in $28.9 \%$ of state hospitals active in Turkey. Of the total 2957 staff working in PCCs, $77.6 \%$ are health care professionals, with $9.9 \%$ being doctors. Home health care service (HHCS) units are available in $76.3 \%$ of hospitals with PCCs. Service was offered to 48,953 patients in PCCs, $5.7 \%$ of whom were transferred to HHCS in an integrational manner.

\section{CONCLUSION}

Integration between PCCs and HHCS remains at an inadequate level. We believe that the benefits of integration should be observed by patients, relatives, and health personnel, thereby increasing awareness and accelerating integration. In addition, we believe that hospital information management systems can be used for this purpose and software programs can be developed to accelerate integration between these 2 units.

Keywords: Coordination, home health care, health professionals, integration, palliative care

\section{INTRODUCTION}

Palliative care is the comprehensive and integrated care of patients and their families who are facing problems related to life-threatening diseases. It used to be a care philosophy of approach organized and structured at a high level with multidisciplinary health care providers (I). In palliative care units, symptom control is targetted rather than treating the primary disease to enhance the patient's quality of life. In addition to the symptom control of the primary disease, the physical, social, psychological, and moral requirements of the patients are focused

The need for palliative care has increased worldwide owing to prolonged life expectancies and an increasing aging population, as well as an increase in the frequency of noninfectious diseases and cancer. Approximately 40 million people need palliative care annually (2). According to estimations, worldwide, 377 of I00,000 individuals older than the age of I5 years and 63100,000 individuals younger than 15 years will need palliative care at the end of their life (I). However, only $14 \%$ of the people worldwide in need of palliative care are able to obtain it (2). 
In 20ll, it was stated that advanced integration of palliative care services with the primary services was available in only $20(8.5 \%)$ out of 234 countries. Only limited and insolated palliative care services are available in 75 countries (31.6\%), and no palliative care services are available in 98 countries (42\%) (3). In 2011,136 (58\%) out of 234 countries implemented palliative care services in I or more hospitals (I). To integrate evidence-based, cost effective, and equitable palliative care services to health services at every level, palliative care policies to support extensive consolidation of health systems have to be developed, empowered, and applied (4).

At the beginning of the 1990s, it was noticed that there was a need for a palliative care program in Turkey, but it could not go beyond providing pain management to cancer patients. A 5-year national cancer control program, including palliative care, was declared in 2009, and palliative care was acknowledged as medical discipline through the "Palya Turk" project in 2010 (5). The legislation for the opening of palliative care clinics (PCCs) in Turkey was issued in 2014. PCC bed capacity was planned to be half of the bed capacity of the intensive care unit available in the same hospital, with such planning limited to the state hospitals (6). Palliative care and home health care services (HHCS) became integrated services, and the cooperation of these 2 disciplines was essential. After completing treatment of the patients in PCCs, their follow-up period is managed at home by HHCS units for their medical, psychological, and social needs to provide the maximum possibility of achievement of better quality of life. Legislative studies have been made for this goal and HHCSs, which began in 2011 has was integrated with PCC in 2015 (6).

The aims of the current study were to analyze PCC distribution and locations within the structure of state hospitals in Turkey, along with human resources, and to evaluate the integration of PCCs with HHCSs.

\section{MATERIAL and METHODS}

Data of PCCs between January 2015 and February 2017 were analyzed in this study. Written consent of the T.R. Ministry of Health was provided to acquire and use data for this study. Therefore, ethics committee approval was not required. The

\section{Main Points:}

- $\quad$ PCCs are available in $28.9 \%$ of the hospitals in Turkey, and $76.3 \%$ of the hospitals with a PCC has an HHCS unit. There are 2429 beds in PCCs, $63.3 \%$ of which are qualitative.

- Integration between PCCs and HHCS remains at an inadequate level.

- The benefits of integration should be observed by patients, relatives, and health personnel, thereby increasing awareness and accelerating integration.

- Hospital information management systems can be used for the purpose of integration and software programs can be developed to accelerate integration between PCCs and HHCS units. Future studies are also needed in order to analyze the effect of integration between PCCs and HHCSs on morbidity and mortality. appropriate forms have been officially submitted to all hospitals linked to the Ministry that have registered PCCs within their structure. The roles of the hospitals having PCCs, the number of beds in these clinics, the number of qualitative beds, the number of health care professionals, and the integration of the PCC with $\mathrm{HHCS}$ s were questioned using the prepared form. Forms were completed by the appropriate individuals in charge. The database from the Ministry and all acquired data were compared to determine correctitude of the information. After evaluation, any inconsistencies were eliminated.

\section{Statistical Analysis}

SPSS software (version 24.0; IBM SPSS Corp.; Armonk, NY, USA) was used for descriptive statistical analysis of the data.

\section{Definitions}

\section{Role of the Hospital and Classification}

The role of the state hospitals and their classification are defined with a circular (7). According to this classification:

(I) Group A-I General Hospitals: Treatment institutions with general beds that are authorized to provide training in a minimum of 5 medical specialities completed training personnel are grouped accordingly, and where third level treatment and rehabilitation service are given, training and research activities are conducted, and specialists are trained and fellowships are given.

(2) Group A-II General Hospitals: General hospitals that do not have active training and research in the provinces, with a health center or the province linked to those centers.

(3) Group B General Hospitals: General hospitals thoseare located in the provinces, other than the A-I and A-II hospitals, which are located or in the improved districts.

(4) Group C General Hospitals: Hospitals that are active in the improved districts or the districts linked to the centers improved within the content of health region planning regarding health services offered, with specialists providing care in the 4 main specialities (internal diseases, general surgery, gynecology and obstetrics, and pediatrics). In addition, specialists are available at least in 2 other specialties and with at least a first step intensive care unit and first level emergency service.

(5) Group D General Hospitals: Hospitals having at least I specialist, including a primary care physician (family doctor) and active in the districts linked to the improved districts and those having at least 25 patient beds.

(6) Group E General Hospitals: Hospitals having fewer than 25 patient beds and those where diagnosis and treatment services are offered along with health services at the first step given in the same structure.

\section{Qualitative Bed}

Defines the bed where a bath and toilet are located inside the room, and a television, telephone, dining table, and companion sofa bed are provided. 


\section{RESULTS}

According to our study, among all government hospitals (8) $27 \%$ of PCCs are located in Group B hospitals, 24\% in Group C hospitals, 21\% in Group A-II hospitals, and 19\% in Group A-I hospitals. PCCs are not available in Group E hospitals. PCCs are available in $28.9 \%$ of state hospitals active countrywide (Table I). There are 2429 patient beds in PCCs countrywide, and $63.3 \%$ of the beds in PCCs are qualitative (Table 2). There are 2957 total staff working in PCCs, $77.6 \%$ of whom are health care professionals. Of these, $9.9 \%$ are doctors (Table 3 ). HHCS units are available in $76.3 \%(n=152)$ of the hospitals with PCCs (Table 4). This service is offered to 48,953 patients in PCCs, and $5.7 \%$ ( $n=2837$ ) of these patients are transferred to HHCSs (Table 5).

\section{DISCUSSION}

PCCs are available in 28.9\% of the hospitals in Turkey, and $76.3 \%$ of the hospitals with a PCC has an HHCS unit. There are 2429 beds in PCCs, $63.3 \%$ of which are qualitative. This constitutes $1.8 \%$ of all public beds A total of $5.7 \%$ of patients are transferred to HHCSs from PCCs. There are 0.61 nurses per palliative care bed and 1.14 doctors per PCC.

TABLE I. Distribution of State Hospitals and Palliative Care Clinics in 2017 According to the Role of the Hospitals

\begin{tabular}{|lccc|} 
Hospital Role & $\begin{array}{c}\text { Hospital (*), } \\
\mathbf{n}\end{array}$ & $\begin{array}{c}\text { Palliative } \\
\text { Care Clinic, } \\
\mathbf{n}(\%)\end{array}$ & $\begin{array}{c}\text { Rate of Availability } \\
\text { of Palliative Care } \\
\text { Clinic Within the } \\
\text { Structure, \% }\end{array}$ \\
\hline Al & 86 & $38(19 \%)$ & $44.2 \%$ \\
A2 & 107 & $41(21 \%)$ & $38.3 \%$ \\
B & 123 & $54(27 \%)$ & $43.9 \%$ \\
C & 163 & $48(24 \%)$ & $29.4 \%$ \\
D & 123 & $18(9 \%)$ & $14.6 \%$ \\
E & 86 & 0 & 0 \\
Total & 688 & 199 & $28.9 \%$ \\
\hline *: (8) & & & \\
\hline
\end{tabular}

TABLE 2. Bed and Qualitative Bed Situation in Palliative Care Clinics

\begin{tabular}{|lccc|}
\hline & $\begin{array}{c}\text { Number of Recently } \\
\text { Activated } \\
\text { PCCs, } \mathbf{n}\end{array}$ & $\begin{array}{c}\text { Number of } \\
\text { beds in } \\
\text { PCCs, } \mathbf{n}\end{array}$ & $\begin{array}{c}\text { Number of } \\
\text { Qualitative Beds } \\
\text { and Rate, n (\%) }\end{array}$ \\
\hline 2015 & 98 & 1.294 & $757(58.5 \%)$ \\
2016 & 79 & 865 & $559(64.6 \%)$ \\
2017 (January- & 22 & 270 & $222(82.2 \%)$ \\
February) & 199 & 2.429 & $1.538(63.3 \%)$ \\
Total & & & \\
\hline
\end{tabular}

In our study, the number of beds in PCCs was increased by 1.87, whereas the number of qualitative beds was increased by 2.03 . Although PCCs are generally available in Group A-I, A-II, and $B$ hospitals located in the province centers, they are rapidly expanding to Group C and D hospitals located in districts as well. Policies of the Ministry are considered to be effective in light of such rapid expansion and increases. The number of beds recommended for hospice and palliative care in Europe is 80 to 100 per $1,000,000$ population $(9,10)$.

According to our data, 30.4 beds are currently serving each $1,000,000$ population countrywide, which is far below the recommendation. PCCs are available in $28.9 \%$ of the state hospitals, a rate that has to be increased. In addition, we believe that the target may come closer together if private and university hospitals were included in the planning. A total of 2957 personnel currently work in PCCs countrywide, of whom $77.6 \%$ are health personnel. Of these, $9.9 \%$ are doctors and $65 \%$ are nurses. The recommendation according to international standards is I nurse per bed $(9,10)$. Currently in Turkey, our study found the number of nurses per bed is 0.61 , which is quite low.

The integration of palliative care with home care and having transfers made in harmony will assure that patients receive the proper health and care service easily (I, II). Such integration and harmony would also provide support to the health economy through the economical use of resources (6). According to our study, 76.3\% of PCCs countrywide are integrated with HHCs. However, the rate of patients transferred to HHCs is very low at $5.7 \%$. Factors causing this situation must be examined first and the integration setup should be reevaluated. PCCs receive most of their patients from intensive care clinics. Along with an increase in the number of beds in PCCs, the tendency for increase for beds in intensive care units, especially in state hospitals, is expected to drop. However, this expectation was not reflected as of 2017 (Figure I). It is believed that an increase in the number of intensive care beds continues, as the palliative care field had just started in 2015 and needs in this field are very high. Studies conducted in this field are necessary, as PCCs will affect occupation rates and the number of admission dates of intensive care beds.

Implementation of palliative care services have an important role, especially in the management of end-of-life patients. As HHCs run by state hospitals attached to the Ministry of Health cover the entire population free of charge, this is an important development in the field of social medicine. Implementations aligned with health policies are rapidly extended countrywide. Although both units are localized in the same hospital, integration between PCCs and HHCSs remains at an inadequate level.

TABLE 3. Number of the Health Care Professionals working in Palliative Care Clinics in Turkey, February 2017

\begin{tabular}{|c|c|c|c|c|c|c|}
\hline \multicolumn{7}{|c|}{ Healthcare Professionals } \\
\hline Medical Doctor & Nurse & Psychologist & Social Worker & Physiotherapist & Dietician & Total \\
\hline 228 & 1,492 & 149 & 127 & 150 & 150 & 2,296 \\
\hline Spiritual Care Staff & Clinical Support & & Other & & & \\
\hline 67 & 91 & & 503 & & & 661 \\
\hline
\end{tabular}




\begin{tabular}{|c|c|c|}
\hline & $\begin{array}{l}\text { Recently Activated } \\
\text { PCCs, n }\end{array}$ & $\begin{array}{l}\text { Hospitals with PCC and } \\
\text { HHCS Units, n (\%) }\end{array}$ \\
\hline 2015 & 98 & $75(76.5 \%)$ \\
\hline 2016 & 79 & $58(73.4 \%)$ \\
\hline 2017 (January-February) & 22 & $19(86.3 \%)$ \\
\hline Total & 199 & $152(76.3 \%)$ \\
\hline
\end{tabular}

\begin{tabular}{|c|c|c|}
\hline & $\begin{array}{l}\text { Number of Patients } \\
\text { (n) }\end{array}$ & $\begin{array}{l}\text { Number and Rate of } \\
\text { Patients Transferred to } \\
\text { HHCS Units, } n(\%)\end{array}$ \\
\hline 2015 & 8,815 & $452(5.1 \%)$ \\
\hline 2016 & 31,958 & $1,952(5.9 \%)$ \\
\hline 2017 (January-February) & 8,180 & $433(5.2 \%)$ \\
\hline Total & 48,953 & $2,837(5.7 \%)$ \\
\hline
\end{tabular}

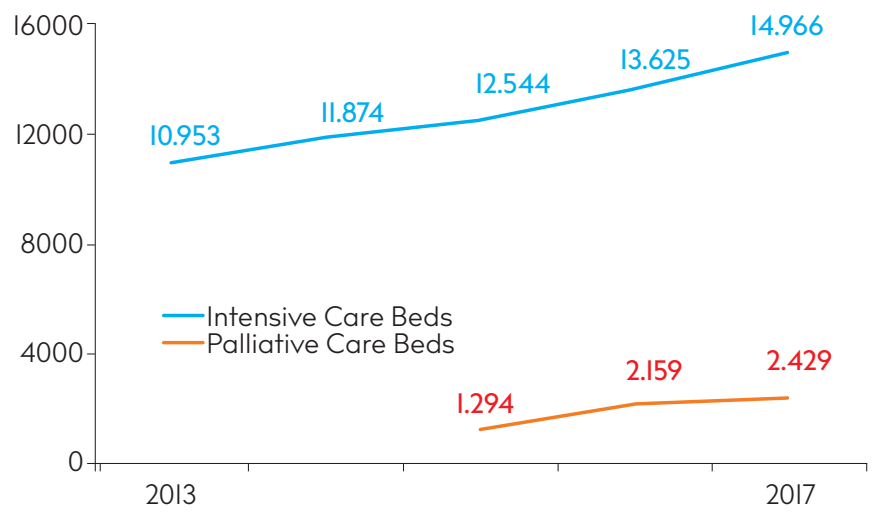

FIGURE I. Increase Tendency of the Number of Intensive Care Beds and Palliative Care Beds

We believe that benefits of such integration would be observed by the patients, their relatives, and health care professionals, increasing awareness and accelerating integration in long-term implementations. If short-term positive feedback is expected concerning the satisfactory quantitative interaction between PCCs and HHCSs, some applications are provided and should be developed. These applications must be independent of demand of patients and reference of health care professionals. We believe hospital information management systems can be used for this purpose and that software programs can be developed to help accelerate the integration between these two units. We also believe that there is a need for future studies analyzing the effect of integration between PCCs and HHCSs on morbidity and mortality.

Ethics Committee Approval: Written consent of the T.R. Ministry of Health was provided to acquire and use data for this study, therefore local ethics committee approval was not recieved. Written consent was obtained from the Ministry of Health by official correspondence (number 326933/13-622.03)

Informed Consent: Written consent was obtained from the Ministry of Health by official correspondence.

Peer-review: Externally peer-reviewed.

Author contributions: Concept - M.H.T., T.Ö., F.G., C..Ö.; Design - M.H.T., T.Ö., F.G., C..Ö.; Supervision - T.Ö., F.G.; Resource - F.G.; Materials - T.Ö.; Data Collection and/or Processing - F.G.; Analysis and/or Interpretation - T.Ö., F.G.; Literature Search - M.H.T., C..Ö.; Writing - M.H.T., C..Ö.; Critical Reviews - M.H.T., T.Ö., F.G., C..Ö.

Acknowledgements: The authors would like to thank all the health care workers who dedicate in the settings of palliative care units all through the country.

Conflict of Interest: Authors have no conflicts of interest to declare.

Financial Disclosure: The authors declared that this study has received no financial support.

\section{REFERENCES}

I. Global Atlas of Palliative Care at the End of Life. Worldwide Palliative Care Alliance (WPCA) and World Health Organization. January 2014.

2. http://www.who.int/en/news-room/fact-sheets/detail/palliative-care

3. Lynch T, Connor S, Clark D. Mapping levels of palliative care development: a global update. J Pain Symptom Manage 2013; 45(6): 1094-106. [Crossref]

4. Sixty-Seventh World Health Assembly. Strengthening of palliative care as a component of comprehensive care throughout the life course. Agenda item 15.5, WHA67.19- 24 May 2014.

5. Ozgul N, Koc O, Gultekin M, Goksel F, Kerman S, Tanyeri P, et al. Opioids for Cancer Pain: Availability, Accessibility, and Regulatory Barriers in Turkey and Pallia-Turk Project. J Pediatr Hematol Oncol 20II; 33(Suppl I): S29-S32. [Crossref]

6. T.R. Ministry of Health Directive for Palliative Care Services Principles and Procedures.

7. Circular of T.R. Ministry of Health No. 2010/50 for Regional Health Planning.

8. State Hospitals Statistics Report 2017, T.R. Ministry of Health -General Directorate of State Hospitals, Ankara, 2018.

9. Payne S, Radbruch L. White Paper on standards and norms for hospice and palliative care in Europe: Part I. European Journal of Palliative Care 2009; 16(6): 278-89.

10. Radbruch L, Payne S. White Paper on standards and norms for hospice and palliative care in Europe: part 2. European Journal of Palliative Care 20I0; 17(I): 22-33.

II. Planning and implementing palliative care services: a guide for program managers. World Health Organization 2016. 